\title{
LEÓN FELIPE ALISTA A DON QUIJOTE EN EL BANDO REPUBLICANO
}

\author{
Raquel Arias Careaga \\ Universidad Autónoma de Madrid \\ raquel.arias@uam.es
}

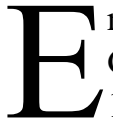
n Tábara, pueblo de la provincia de Zamora donde nació Felipe Camino Galicia - el que iba a convertirse en el poeta León Felipe-, hubo hacia 1450, según cuenta fray Alonso Espina, una cabeza parlante. En la historia de esta cabeza se inspiraría Miguel de Cervantes para escribir uno de los episodios de El ingenioso hidalgo don Quijote de la Mancha. Este libro iba a resultar de inestimable ayuda para el poeta que siglos después se encontraría con él en un lugar muy similar a aquel donde se dice que fue gestada la novela más importante de la cultura española, es decir, en una cárcel. La vida de farmacéutico de Felipe Camino Galicia, cada vez más complicada, le había llevado a entramparse, a pedir créditos, a dedicarse al juego más que a las fórmulas de botica, hasta que llega un momento en que deja todo y se sumerge en el mundo del teatro. Serán dos años de dar tumbos con una y otra compañía, pero al final es reconocido por sus acreedores y detenido. Cuando se cumplía el tercer centenario de la publicación de la segunda parte de El ingenioso hidalgo don Quijote de la Mancha, en 1915, es condenado a un año, ocho meses y veintiún días de cárcel en Santander (García Cantalapiedra: 39-40) ${ }^{1}$, tiempo que dedicó a leer el Quijote (Pliego: 112). De aquella primera lectura nacerán catorce sonetos sobre el tema de la novela de Cervantes, aunque posteriormente los destruyó (Pliego: 18). Su acercamiento a la poesía nace, por tanto, gracias a un encierro obligado y al estímulo que supone aquella lectura, y acabará cristalizando en un libro titulado Versos y oraciones del
\end{abstract}

\footnotetext{
1 En el poema «Escuela» el propio poeta afirmaba que su condena había sido a tres años, dato que se ha repetido frecuentemente. La causa de su paso por la cárcel tiene que ver con la farmacia que regentaba en aquellos años: la imposibilidad de devolver los préstamos solicitados le lleva a una huida que terminará en manos de sus acreedores y con la pena de prisión mencionada.
}

Edad de Oro, XXXIV (2015), pp. 57-68, ISSN: 0212-0429 - DOI http://dx.doi.org/10.15366/edadoro2015.34.003 
caminante $^{2}$, que no puede por menos que hacernos pensar en un «poeta andante», a imitación del admirado personaje de Cervantes con el que él mismo se comparará (Rodríguez Puértolas: 444) y que dará a conocer en el Ateneo de Madrid cuatro años después. Es así como ingresa en el grupo de poetas que se van reuniendo bajo la bandera de una España diferente, a la que anhelan modificar.

León Felipe nunca permanecerá demasiado tiempo en España, alternando sus estancias en el país que le vio nacer con los viajes a América; una América que había conocido tras su experiencia en Guinea Ecuatorial como administrador de hospitales y en la que se le abrirán varias puertas gracias a la amistad de Alfonso Reyes. México, Estados Unidos y Panamá, donde le sorprenderá el comienzo de la Guerra Civil como agregado cultural de la República, serán algunos de sus destinos. Tras su participación en la defensa de la República y su forzado exilio, regresará definitivamente a México, aunque realizará un largo viaje de dos años por toda Hispanoamérica a partir de 1946 (Frau: 14). León Felipe morirá en México en 1968.

$\mathrm{Su}$ acercamiento inicial a la poesía está centrado sobre todo en la contemplación del paisaje, que le lleva a una visión histórico idealista cercana a la que habían planteado los intelectuales de la Generación del 98 (Rodríguez Puértolas: 444). De esta observación de España destaca con fuerza el protagonista de la novela cervantina, convirtiéndose en el instrumento que canaliza la indignación producida por el estallido de la Guerra Civil y sus terribles consecuencias para el país. Es indudable que su estancia en Almonacid de Zorita (Guadalajara) en 1919, regentando una farmacia, le pone en contacto directo con un paisaje en el que no resulta difícil intuir el espíritu de don Quijote. Miguel Nieto Nuño llega a afirmar que León Felipe «forjó él su mito, un personaje que llenara la imaginación suya y la de su pueblo con contenidos de actuación. Otro no podía ser que don Quijote de La Mancha; un don Quijote quizá anterior a su propia vida literaria» (Nieto Nuño: 67). El texto de Nieto Nuño sigue con tal acumulación de hipérboles que es mejor dejarlo aquí. Lo que sí es cierto es que el poeta entresaca del personaje literario aquellos aspectos que pueden servirle para construir una metáfora activa, transformadora y menos nostálgica que la que había construido Rubén Darío tanto en verso como en prosa ${ }^{4}$. En palabras de Benito del Pliego (18), «don Quijote como

2 La importancia del título, o al menos de las connotaciones que tiene para el autor es tal, que en 1929 aparecerá su segundo volumen de versos con el mismo título: Versos y oraciones del caminante. Libro II.

3 El autor crea una visión del personaje que trasciende cualquier acercamiento histórico o literario: «rigiéndose por las leyes del mito y habiendo introducido en lo dado como desenvolvimiento histórico el sentido de la justicia, su nacimiento es el brote mismo de la historia, la fundación del primer orden para el hombre, el orden de los tiempos. Avanza la historia en un proceso místico hacia la colmada justicia que habrá de desatar la luz final de la eternidad» (Nieto Nuño: 67).

4 Rubén Darío es sin duda uno de los primeros autores que recupera la esencia del Quijote como 
imagen idealista y caricaturesca de una rebelión insoslayable y de la derrota anunciada» será una constante de su obra que no le abandonará ya nunca.

La primera aparición del personaje cervantino se registra en el poema «Vencidos...», incluido en Versos y oraciones del caminante. León Felipe observa y relata allí el regreso de un don Quijote vencido en la playa de Barcelona por el caballero de la Blanca Luna, un don Quijote que «va cargado de amargura, / va, vencido, el caballero de retorno a su lugar». La identificación con este héroe vencido es inmediata: «hazme un sitio en tu montura, / caballero derrotado, / hazme un sitio en tu montura / que yo también voy cargado / de amargura / y no puedo batallar». Sin embargo, este no es el caballero andante que se va a su pueblo para morir en la cama después de haber renegado de sí mismo. Este es aquel otro que, aun en esa situación de derrota, busca una salida nueva, un futuro que saldrá también de los libros: «Ponme a la grupa contigo, / caballero del honor, / ponme a la grupa contigo / y llévame a ser contigo / pastor.» (Felipe 1963: 48-49). El personaje recorre y se pasea por las tierras manchegas, espíritu nunca muerto que camina por España como recuerdo de pasadas hazañas, como a la espera de encontrar algún encantamiento que le permita desempolvar sus armas. Sin duda, «don Quijote siempre fue convocado por León Felipe para abrir una nueva realidad, desde el verso, en las circunstancias del presente» (Nieto Nuño: 113).

Es evidente que esta recuperación de la figura cervantina es una de las claves de la época. La celebración del centenario de la publicación en 1905 había supuesto un resurgimiento del interés por la primera novela moderna, en palabras de Américo Castro, que había de llegar a todos los ámbitos de la cultura de la época: «León Felipe participaba del momento actualizador en filología y literatura que hacia Don Quijote mantenían las generaciones de Unamuno y Ortega» (Nieto Nuño: 106). Es muy interesante este despertar de toda una sociedad que anhela un cambio en su realidad y se vuelca en la novela de Cervantes para encontrar en ella una herramienta que haga posible, al menos, la reflexión necesaria para encontrar un camino nuevo. Rubén Darío, como se apuntó, es uno de los que abre esta senda, pero en el campo de la filología será Américo Castro quien dé el vuelco fundamental que obligará a releer la novela con unas claves hasta ese momento ignoradas o desechadas. La gran novedad dentro del panorama filológico que se acercaba a Cervantes como a un escritor sin relieve que había logrado, a pesar de sí mismo, una obra genial, fue el esfuerzo de Castro por ubicar el texto de Cervantes en las coordenadas de su época (en realidad, eso es lo que hace el gran estudioso siempre que se enfrenta con las grandes obras o figuras de la literatura

raíz de lo hispánico para enfrentarlo al pragmatismo anglosajón. No solo son destacables las «Letanías de nuestro señor don Quijote», también es fundamental el cuento titulado «D. Q.», inspirado por la derrota sufrida por España en Cuba, en 1898, antes los Estados Unidos de América del Norte. 
española). Sin las peculiaridades de la España del Siglo de Oro, nada de lo que se diga tendrá demasiado sentido: «De haber conocido el espíritu burgués, seríamos hoy como Suiza u Holanda; pero no se habría escrito el Quijote y toda América hablaría inglés» (Castro 2015: 267). Situar a Cervantes en medio de la obsesión religiosa, la limpieza de sangre, el rechazo de los conversos implica resignificar sus palabras y situarlas al fin en el marco en que fueron pronunciadas. Este nuevo acercamiento a Cervantes que se plasma en El pensamiento de Cervantes, publicado en 1925, puso en pie de guerra a intelectuales y filólogos, que hasta hoy no han sido capaces de aceptar las transgresoras sugerencias de don Américo, prefiriendo al escritor tradicional que solo podía ser explicado por un ataque súbito de genialidad de la que él mismo no era responsable. Esta actitud está en la base de la profunda batalla que se entabla alrededor de la personificación de uno de los mitos más importantes de la cultura española, precisamente por el deseo de Castro de alejar la visión mítica para sustituirla por la visión histórica.

León Felipe, en medio de este renacimiento del hidalgo loco, prefiere retomar el mito para actualizarlo e incorporarlo a la España del momento como signo dotado de sentido ${ }^{5}$. No le preocupan los debates más o menos científicos, filológicos e historicistas alrededor de la novela, sino la carga semántica del personaje creado por Cervantes. El poeta hace de la derrota del caballero el nexo de unión, primero en un plano personal y después en un plano colectivo e histórico. Todo esto indica, sin duda, que hay una apropiación de don Quijote desde distintas posturas políticas, y León Felipe, identificado con la triste figura del caballero, no duda en situarlo en la lucha histórica que vendrá después. Para este proceso que pasa desde la unión personal a la colectiva, se utiliza un concepto esencial, la justicia:

Cuando don Quijote pronunció por primera vez la palabra justicia en el Campo de Montiel... sonó en la llanura manchega una carcajada estrepitosa que ha venido rodando de siglo en siglo por la tierra, por el mar y por el viento hasta clavarse en la garganta de todos los hombres con una mueca cínica y metálica. ¡Ja, ja, ja! ¡Reíos!... ¡Reíos todos! Que la justicia no es más que una risa grotesca. ¡Ja, ja, ja!

Pero el payaso se yergue y se vuelve contra el empresario, contra los hombres y los dioses gritando:

¡Basta!

¡Basta ya! ¡Basta ya de risas!

¿Que no se ría nadie! ¿Que no se ría nadie! Mi sangre de clown vale tanto como la sangre de los cristos. ¡Yo no soy un payaso! ¡Yo soy Prometeo! Vengo de la casta

Un ejemplo es la identificación del Quijote con nada menos que la Hispanidad: «Hispanidad será aquel gesto vencido, apasionado y loco del hidalgo manchego. / Sobre él los hombres levantarán mañana el mito quijotesco / y hablará de hispanidad la historia cuando todos los españoles se hayan muerto. / Para crear la hispanidad hay que morirse porque sobra el cuerpo. / Murió el héroe y morirá su pueblo» (Felipe 1963: 252). 
de los viejos redentores del mundo, y he dado mi sangre, no para hacer reír a los dioses y a los hombres sino para fecundar el yermo.

¿Entendéis ahora? Don Quijote es el poeta prometeico que se escapa de su crónica y entra en la Historia hecho símbolo y carne, vestido de payaso y gritando por todos los caminos: ¡Justicia! ¡Justicia! ¡Justicia! (Felipe 1963: 983-984)

La lectura que de la novela había hecho León Felipe estaba marcada por su estancia en la cárcel, destacando por encima de todo la búsqueda de una justicia que escapase del estrecho concepto social y jurídico. Pero más adelante la justicia, entendida como una necesidad histórica que elimine la desigualdad, entroncará además con el devenir de una España castigada hasta sus cimientos por la iniquidad que pone en pie la Guerra Civil. De esta forma, don Quijote se convierte en un refugio y una salvaguarda: «¡La Justicia! La única Justicia que aún queda en el mundo (las últimas palabras de don Quijote, el testamento de don Quijote, la esencia de España)» (Felipe 1963: 124). Lo que había conseguido Cervantes era dar con las entrañas de una patria condenada desde siempre. Si «en Cervantes (en El Quijote) no hay invención y apenas artificio; el necesario nada más para darle forma poemática a la realidad» (Felipe 1963: 122-123), el final de la novela se convierte en una terrible premonición del futuro:

Cuando el bachiller y unas fuerzas confabuladas derrotan a don Quijote en la playa de Barcelona, el poeta sabe que más tarde, tal vez tres siglos más tarde, el mismo Bachiller y las mismas fuerzas confabuladas han de derrotar a España para siempre. La verdad poética se adelanta a la verdad histórica. El poeta habla primero. Y cuando Cervantes mata a don Quijote, es cuando España se acaba en realidad.

España está muerta. Muerta. Detrás de Franco vendrán los enterradores y los arqueólogos. Y los buitres y las zorras que acechan en las cumbres. ¿Qué otra cosa esperáis? ¿Volver vosotros de nuevo, cuando se derrumbe la harca de los generales? ¡Los éxodos no vuelven! ¿Y a qué ibais a volver? ¿A darle otra vuelta al aristón? ¡Ya no hay más vueltas! (Felipe 1963: 123)

La implicación de León Felipe con la República española y su participación en la Guerra Civil (no olvidemos que abandona la seguridad de su puesto de profesor en Panamá para sumergirse en el fragor de la lucha ${ }^{6}$ ) arrastra todo lo que ha sido su visión del mundo hasta ese momento, y así don Quijote se convierte en herramienta en esta nueva etapa: «Don Quijote es un poeta de esta clase. Es un

\footnotetext{
6 Hay que recordar el texto «Goodbye, Panamá!», donde expone la necesidad de participar en la defensa del gobierno republicano legítimo frente a sus acomodados compatriotas instalados en aquel país, bastante satisfechos con el alzamiento franquista. Su clara postura política supuso que de forma inmediata «se le impide publicar en los periódicos nacionales y a finales de agosto, justo antes de abandonar el país, se le prohíbe también retransmitir por radio el mensaje que con el título de "Goodbye, Panamá!" había redactado» (Pliego: 31).
} 
poeta activo y de trasbordo. Y se diferencia de todos los demás poetas ordinarios del mundo en que quiere escribir sus poemas no con la punta de la pluma, sino con la punta de la lanza» (Felipe 1963: 229). Pondrá como ejemplo de ello lo que él considera la verdadera primera aventura del caballero andante, la llegada a la venta donde será armado caballero, con la transformación esencial a que somete la realidad que se encuentra:

Cuando don Quijote toma al ventero ladrón por un caballero cortés y hospitalario, a las prostitutas descaradas por doncellas hermosísimas, la venta por un albergue decoroso, el pan negro por pan candeal y el silbo del capador de cerdos por una música acogedora, dice que en el mundo no debe haber ni hombres ladrones ni amor mercenario ni comida escasa ni albergue oscuro ni música horrible, y que nada de esto habría si no fuese por los malos encantadores. Estos encantadores se llaman de otra manera. Don Quijote sabe muy bien cuál es su nombre exacto, pero para denunciarlos se vale también de una metáfora. (Felipe 1963: 230)

Esta reivindicación de la transformación de la realidad no en el plano de la ficción sino en el de la acción, presupone la reivindicación de la locura, raíz de esa capacidad revolucionaria en la obra de Cervantes: «Ya no hay locos, amigos, ya no hay locos. Se murió aquel manchego, / aquel estrafalario fantasma del desierto / y... ni en España hay locos. Todo el mundo está cuerdo, / terrible, monstruosamente cuerdo» (Felipe 1963: 261).

Como tantos españoles y extranjeros, León Felipe es consciente de lo que está en juego en España en 1936 y eso es lo que le obliga a unirse a la lucha en su país. Así de claro se lo explicó a los españoles radicados en Panamá que saludaban el golpe de estado con alegría: «Y el sol de España no alumbrará para vosotros mañana, porque el sol de España —oídlo otra vez-o se alza ahora para alumbrar una tierra de justicia y de dignidad humanas, donde no cabéis vosotros, o no se alza para nadie» (Felipe 1963: 950).

Todas estas circunstancias están en la base de uno de los momentos más importantes en la actividad de León Felipe durante su última estancia en España, antes de partir definitivamente para el exilio7. Los días 5 y 11 de febrero de 1937 participa en un acto donde da una conferencia en la Casa de la Cultura de Valencia, charla que se propone como un reflejo idealista de la visión que sobre España y su esencia se está forjando desde el otro lado. Con herramientas muy similares a las que la derecha española está manejando, León Felipe reivindica una historia esencialista, una patria existente a lo largo de los siglos, invariable, anterior a sí misma. Pero en este caso, la intención del poeta es construir una tradición que

Debo los datos que siguen sobre las intervenciones de León Felipe durante la Guerra Civil a la generosidad de Francisco Layna y a sus investigaciones para el libro que está preparando sobre las lecturas políticas del Quijote en esta época. 
salvaguarde la lucha revolucionaria en la que se encuentra inmerso: «la exaltación religiosa huyó de Castilla hace más de tres siglos, y vuelve ahora con la Revolución, con los revolucionarios, y vuelve a hacer su nido en la meseta otra vez, como siempre» ${ }^{8}$ (1963: 979). La intrínseca relación que se establece entre fe y Revolución no es más que un ejemplo de la amplia perspectiva con que encara León Felipe el hecho o el sentimiento religioso, la pasión del hombre por construir un mundo mejor, un mundo más humano. La identificación con la lucha en defensa del gobierno republicano es clara, y así continúa matizando la distancia que separa ese sentimiento religioso del que habla de la religión tradicional: «Pero no en los conventos. El sentimiento religioso ahora se seculariza; se desclericaliza, se humaniza y se encarna en hombres laicos que se erguirán sobre la meseta con una voz no monacal, sino castellana. Y Castilla hablará otra vez, no Roma. Ni Roma ni Moscú, ya lo hemos dicho. Madrid es mío, Madrid es nuestro» (1963: 979). Como es obvio, León Felipe defiende la peculiaridad española frente a cualquier injerencia externa, venga del Vaticano o del Partido Comunista Soviético. Si esta postura es importante, lo es en relación con la apropiación de la patria que se está llevando a cabo desde el bando que aglutina a los golpistas y que se ha denominado a sí mismo «nacional». Hay una verdadera angustia por el expolio a que está siendo sometido el pasado cultural español desde la perspectiva nacional católica, de ahí estas palabras en el mismo discurso:

Si la desventura de una escaramuza guerrera lo pusiera de improviso en otras manos y cambiase políticamente de amos, Castilla seguiría siendo nuestra, porque creándonos ella, la hemos creado también nosotros, los poetas, los artistas, los santos y los místicos, que también están a nuestro lado. Hay algo más que surcos, tierra pelada y viejos castillos en Castilla. Nuestra sangre, Machado, y lo que ha arado allí nuestra angustia, la quilla dolorida de nuestra alma. (1963: 979)

En realidad, como decíamos, el poeta se sirve de las mismas herramientas dialécticas que sus enemigos para mantener una visión de España transcendental y ajena al devenir histórico. En este proceso le será de mucha utilidad recurrir a los mitos que han ido forjando la imagen de España, pero no de otra España, sino de la misma por la que se lucha desde el frente enemigo. Es interesante observar de qué manera se van a resignificar los mismos elementos que constituyen el imaginario colectivo de una nación para defender con ellos propuestas tan divergentes hacia el futuro. Los signos quedan así de algún modo vacíos de contenido o, en todo caso, para una parte de la intelectualidad española resultaba imposible aceptar los significados que se les habían dado. Sigue León Felipe su conferencia: «¿Y

8 Las palabras de León Felipe en esta conferencia se reprodujeron en Hora de España, 6 (1937): 11-22. Están recogidas en las Obras completas, por las que cito, bajo el título de «Universalidad y exaltación (la luz universal de Castilla)». 
por qué han de ser ellos, los traidores y los asesinos, la tradición religiosa de España, si esta revolución no es más que una búsqueda de la Justicia, de la Luz, de la Verdad y de la Vida, que son los atributos de la Divinidad? $»^{9}$

Estas palabras últimas enlazan directamente con la visión que del personaje cervantino tiene el poeta. Pero no serán estas sus únicas declaraciones sobre el tema en medio del fragor de la guerra. El mismo año 1937, el 8 de febrero, aparecerá un artículo en el diario El Sol bajo el título «Poesía integral. Don Quijote toma las armas». El mito del caballero andante le sirve para construir con él un pilar más de la esencialidad hispana: «Don Quijote y Sancho son las esencias legítimas y eternas de nuestra raza y de nuestra Historia» (Felipe 1937: 4). La diferencia fundamental estriba en que desde la España tradicional y católica el personaje cervantino siempre había resultado un tanto incómodo. Su ambigüedad, su locura, su derrota, no habían sido nunca bien aceptadas por la España del Imperio que esperaba recuperar Franco con la ayuda de la ideología nacional católica. Muy bien lo había señalado ya Américo Castro cuando decía que «Cervantes no encarnaba los altos principios que, desde su cima, regían la estructura de la España imperial» (Castro 1974: 33). Las palabras de don Américo se referían al rechazo que Manuel de Montoliu había expresado contra Cervantes al poco de terminada la guerra en su artículo «En busca del poeta nacional de España», publicado en La Prensa de Buenos Aires. Como sugería el título de ese artículo, Cervantes no merecía ser considerado como "poeta nacional», dado su escaso compromiso con los valores imperiales, ya que, como comentaba Américo Castro, para Montoliu «el Caballero de la Triste Figura, encarnación suprema de la filosofía del desengaño, es el heraldo de la inminente debilitación de la unidad espiritual del Imperio» (Castro 1974: 33; Arias: 352). Este rechazo de la figura de don Quijote tiene que ver sin duda con la apropiación que de ella se había hecho desde el bando republicano por una intelectualidad progresista, izquierdista, moderna, anticlerical y científica como la que Américo Castro encarnaba ${ }^{10}$. En el caso de León Felipe, la figura de don Quijote adquiere las mismas proporciones míticas que se le habían otorgado al Cid, por ejemplo, entre otros ${ }^{11}$. Afirmaba en El Sol: «Don Quijote era, es y será hasta el última día de su vida el señor de esta prole hispana que anda pidiendo justicia por el mundo. Y si os molesta la palabra Señor, vamos a cambiarla. Don Quijote es el gran camarada, nuestro gran camarada» (Felipe 1937: 4). $Y$ aquella identificación íntima que había experimentado el poeta trasciende

$9 \quad A B C$, jueves 11 de febrero de 1937, p. 13. El diario $A B C$, que también se hizo eco de la conferencia, reprodujo fragmentos que no aparecían en Hora de España, como este que se cita aquí. Señalo en cada caso el medio en que apareció publicado el texto citado en concreto.

10 Sobre esto remito a mi artículo citado en la bibliografía.

11 Es de obligada consulta el libro de Miguel-Antxo Murado (2013) sobre la manipulación a que fue sometido el manuscrito de poema del Cid por parte de Menéndez Pidal y sobre la creación literaria de algunos de los mitos básicos sobre los que se asienta la historia de España. 
hacia la colectividad popular: «[Don Quijote] está aquí luchando con nosotros. Yo le he visto en todas partes con Sancho de la mano». El espíritu del personaje y de la novela cervantina se encarna en el pueblo español que está luchando contra el avance del fascismo.

La metáfora le sirvió a León Felipe para criticar la supuesta neutralidad de las potencias europeas en la guerra de España, reclamando el rearme del viejo símbolo de la caballería española:

Y ahora, lo único que tenemos que hacer con él es lo que yo intenté decir en el Congreso de Ayuda a España que se celebró en París y que no me dejaron decir. Era esto, sobre poco más o menos. Los españoles agradecemos mucho vuestra caridad y esas hilas y bálsamos que nos mandáis para restañar las heridas de don Quijote; pero lo agradeceríamos mucho más que le proporcionaseis una lanza nueva y un escudo moderno.

Se lo proporcionaremos nosotros, porque hay que armar a don Quijote. Y hay que armarlo bien. Hay que armarlo, cueste lo que cueste para ahora y para después de la guerra, porque nadie, nadie en el mundo tiene tanto derecho a estar armado como este gran camarada del amor y de la justicia. (Felipe 1937: 4)

El reconocimiento internacional de la obra de Cervantes sirve a León Felipe para apelar ante Europa y pedir una implicación que supondría salvar algo más que a un gobierno coyuntural. La importancia de este discurso del poeta es clave, ya que reafirma como propia una tradición que les está siendo arrebatada. Al contrario de lo que había hecho Américo Castro al proponer una nueva lectura del Quijote inmerso en las condiciones históricas que le dieron su existencia, impidiendo así que fuera manipulada la obra por una visión falsa e interesada de los intelectuales más tradicionales y retrógrados, León Felipe niega no tanto la lectura, que como vimos coincide con la que podían hacer desde la derecha, sino la apropiación de la cultura española desde sus orígenes por parte del nacional catolicismo:

Don Quijote no es más que un camarada que ha intentado una aventura que a los hombres domésticos les parece una monstruosidad: la de darse por entero a buscar una forma de universalidad mediante el amor y la justicia, donde quepan todos los seres humanos. [...] Ahora bien, en este naufragio yo no veo más que una solución: armar a don Quijote y acabar con los imbéciles, para que España vuelva a recobrar el juicio [...]. Los principios revolucionarios debemos apoyarlos en las fuerzas y en los valores ancestrales legítimos e indestructibles de nuestra raza, de nuestra historia y de nuestra personalidad. ¿Por qué hemos de dejarle la historia a los facciosos, si la historia de España, la noble historia de España es nuestra? La revolución no ha empezado ayer. La revolución, nuestra revolución popular, democrática, proletaria, anárquica y comunal, está implícita en el Romancero y más atrás 
todavía: en nuestras primeras gestas castellanas. Sí, sí, la noble historia de España es nuestra, y la épica también. El Cid y don Quijote son nuestros. (Felipe 1937: 4)

Una revolución, pues, que viene de lejos, la revolución de los postergados, los subalternos, los vencidos por el carro de la historia ${ }^{12}$, una revolución que no está hecha por héroes de una épica alejada del pueblo, sino por seres tan débiles o indefensos como ese mismo pueblo victimado, héroes tan ambiguos que, efectivamente, los defensores del imperio no saben muy bien dónde situar en la tradición que defienden. En este sentido son muy clarificadoras las palabras de Ernesto Giménez Caballero y su incomodidad ante la novela de Cervantes:

La actual publicación en París (ediciones Riéder) de un «Cervantes» redactado en francés directamente por Américo Castro me da ocasión para abordar un tema que hace mucho tiempo pugnaba por desbordárseme en la pluma. Y ese tema no es otro que el de desenmascarar definitivamente al «Quijote» como el libro más antinacional, peligroso, inmoral y trágico de España. Él libro más desterrable de España. El libro más temible y corrosivo de España. El peor veneno de España. Libro sádico que no termina nunca de estrangularnos y dejarnos morir santamente, y así intentar una resurrección y un renacer. (Giménez Caballero 1932: 1)

Estas palabras, escritas en 1932, cuando España es ya una república, no hacen sino sentar la profunda división que entre dos formas de entender la realidad se ha abierto en el país. León Felipe tenía razón, «don Quijote es nuestro», y las palabras de Giménez Caballero indican que a los futuros golpistas les habría gustado encontrar entre los muchos hombres que fusilaron a aquel hidalgo que les impedía cantar las alabanzas de la España eterna desde los siglos que querían gloriosos del Imperio que iban ellos a restaurar. Sin embargo, León Felipe es consciente del oportunismo que dirigirá los intereses de los asesinos y bastardos, como los llama: «Y otro día Franco hará lo mismo con don Quijote. Si ven los falangistas españoles que es negocio y un buen artificio para enmascararse volverán a levantar el brazo y con el negro gesto criminal saludarán al caballero: "Viva don Quijote emperador"» (1963: 981).

Cuando León Felipe publique su último libro, la evolución que ha sufrido en él la imagen de don Quijote le lleva a identificarse ahora ya con el viejo jamelgo que llevaba al caballero andante por las tierras de la Península. Rocinante será el título de este libro y en él el poeta dirá cosas como las siguientes: «los norte-americanos suelen decir: / León-Felipe es un «Don Quijote». / No tanto, gentlemen, no tanto. / Sostengo al héroe nada más. / Y sí puedo decir / y me gusta decir: / que yo soy Rocinante. / No soy el héroe, / pero le llevo sobre el magro espinazo de mis

12 Walter Benjamin hablaba de «una posibilidad revolucionaria en el combate por el pasado oprimido» (en Löwy: 150). 
huesos» (Nieto Nuño: 119). Este poema está dedicado a Ernesto Che Guevara, a quien León Felipe conoció y trató en México. Ernesto Guevara quiso ponerse en contacto con el poeta, cuya poesía conocía, y consiguió entrevistarse con él en un club de republicanos exiliados en la capital mexicana. En 1964, el revolucionario argentino escribió una carta al poeta español: «Tal vez le interese saber que uno de los dos o tres libros que tengo en mi cabecera es El Ciervo; pocas veces puedo leerlo porque todavía en Cuba dormir, o descansar simplemente, es un pecado de lesa dirigencia. El otro día asistí a un acto de gran significación para mí. La sala estaba atestada de obreros entusiastas y había un clima de hombre nuevo en el ambiente. Me afloró una gota del poeta fracasado que llevo dentro y acudí a usted, para polemizar a la distancia. Es mi homenaje; le ruego así lo interprete. Si se siente tentado por el desafío, la invitación vale» (Rojo: 65-66).

Tres años después, cuando el Che fue asesinado en las tierras de Bolivia, entre sus pertenencias se encontró un poema escrito por él. Se trataba de la copia de un poema de León Felipe. Otro don Quijote caído en nombre de la justicia, otro Cristo sacrificado, como decía el poema elegido por Guevara para acompañarle en su último camino.

Recibido: 2/07/2015

Aceptado: 27/07/2015

\section{BIBLIOGRAFÍA}

ANóNIMO (1937). «Universalidad y exaltación. Una maravillosa conferencia de León Felipe». $A B C$ (11 de febrero), p. 13.

ArIAS, Raquel (2014). «La recepción política de El pensamiento de Cervantes», eHumanista/ Cervantes 3, pp. 342-358.

CAstro, Américo (1974). «Cervantes y el Quijote a nueva luz», Cervantes y los casticismos españoles. Madrid: Alfaguara.

(2015). Hacia la mejor España. Los escritos de Américo Castro sobre educación y universidad. Edición de Santiago López-Ríos. Barcelona: Bellaterra.

FeLIPE, León (1937). «Conferencia». Hora de España, 6, pp. 11-22. (1937). «Poesía integral. Don Quijote toma las armas». El Sol (8 de febrero), p. 4. (1963). Obras completas. Buenos Aires: Losada.

FraU, Juan (2002). La teoría literaria de León Felipe. Sevilla: Universidad de Sevilla.

García Cantalapiedra, Aurelio (1984). Los años santanderinos de León Felipe, Santander: Edición del Centenario.

GIMÉNEZ CABALlERo, Ernesto (1932). «Un peligro nacional. La vuelta de Don Quijote», I. El Sol (17 de enero), pp. 1 y 12.

Granados, Vicente (1988): «León Felipe, en Guinea Ecuatorial», EPOS. Revista de Filología (UNED), núm. 4, pp. 411-418. 
Löwy, Michael (2012). Walter Benjamin: aviso de incendio. Una lectura de las tesis «Sobre el concepto de historia». Buenos Aires: Fondo de Cultura Económica.

Murado, Miguel-Antxo (2013). La invención del pasado. Verdad y ficción en la historia de España. Barcelona: Debate.

Nieto Nuño, Miguel (1986). «Memoria de tierra y luz. Castilla-La Mancha en la vida y en la obra de León Felipe», Homenaje de Castilla-La Mancha a León Felipe. Servicio de Publicaciones de la Junta de Comunidades de Castilla-La Mancha, pp. 61-138.

Pliego, Benito del (2002). León Felipe. Madrid: Eneida.

Rodríguez PUÉRTOLAS, Julio (coord.) (2000). Historia social de la literatura española, volumen II. Madrid: Akal.

Rojo, Ricardo (2002). «Mi amigo el Che», reproducido en Fermín Chávez, El Che, Perón y León Felipe. Buenos Aires: Editorial Nueva Generación, 2002, pp. 65-66.

Vegas GonZÁLEZ, Serafín (1986). «La situación humana en la poesía y en el pensamiento de León Felipe», Homenaje de Castilla-La Mancha a León Felipe. Servicio de Publicaciones de la Junta de Comunidades de Castilla-La Mancha, pp. 139-203.

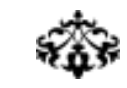

León Felipe alista a don Quijote en el bando republicano

Resumen: La celebración de los centenarios de su publicación (1905 y 1915) supuso el renacimiento de la novela de Cervantes desde comienzos del siglo xx, y la figura de don Quijote se convirtió en símbolo de la España que se quería renovar a partir de 1931. La utilización del mito actualizado tuvo un representante especial en el poeta León Felipe, quien identificó el valor y la derrota del hidalgo manchego con los de la España vencida por Franco.

Palabras clave: León Felipe, Don Quijote, símbolo, República española.

\section{León Felipe enrols don Quixote on the republican band}

ABSTRACT: The celebration of the centenary of Cervantes' novel publication (1905 and 1915) improved the work of Cervantes since the beginning of 20th Century, and Don Quixote becomes an important symbol of the new Spain that started in 1931. León Felipe used that renovated myth in a very special way, and he identified Don Quixote's courage and defeat with Spain's fate caused by Franco.

Keywords: León Felipe, Don Quixote, symbol, Spanish Republic. 
TERESA DE JESÚS (1515-1582)

Guillermo Serés (Universidad Autónoma de Barcelona)

La imaginación de Santa Teresa: virtudes y desatinos de «la loca de la casa»....... 11

Ana Garriga EsPino (Universidad Autónoma de Madrid)

El desafío editorial de las cartas de Teresa de Jesús.

LeCTURAS REPUBLICANAS DEL QUIJOTE

RAQUEL ArIas (Universidad Autónoma de Madrid)

León Felipe alista a don Quijote en el bando republicano. 57

MANUEl LóPez ForJas (Universidad Autónoma de Madrid)

El Quijote y la realidad viva de las Españas: la visión histórica

de Pedro Bosch-Gimpera.

CArmen Madorrán Ayerra (Universidad Autónoma de Madrid)

El Quijote como utopía necesaria: la mirada de Adolfo Sánchez Vázquez 85

\section{OTROS TEMAS}

SònIA BoADAS (Universitat Autònoma de Barcelona)

Libros y librerías: la recepción de Commynes en España 101

Lucila Lobato Osorio (Universidad Nacional Autónoma de México)

La noticia de la muerte de Policisne de Boecia: expresiones de dolor en un libro inconcluso.

María Gutiérrez Padilla (Universidad Nacional Autónoma de México)

La escenografía en el teatro caballeresco 131

ADRIÁn FERnÁNDEZ (Université de Fribourg)

Dos entremeses «auditivos» y sus niveles: hacia un metateatro visual. 145

David González de la Higuera Garrido (Universidad Complutense de Madrid) La visión premonitoria de Alonso en El caballero de Olmedo:

otra recuperación de lo popular

Esther Fernández LóPEz (UNED)

Perseo en la comedia tardobarroca: Ignacio Ferrera y Pasqual 169

Manuel Piqueras Flores (Universidad Autónoma de Madrid)

De La hija de Celestina $a$ La ingeniosa Elena: estructura narrativa, género literario e interpolación 
Dagoberto CÁceres Agullar (Western University Canada)

Realismo incesante: desde Celestina hacia su recepción 201

TeXTOS INÉDITOS

Davinia Rodríguez Ortega (Universidad Pública de Navarra)

Auto sacramental del Juego del Hombre, de Luis Mejía de la Cerda:

edición crítica 


\section{EDAD DE ORO}

Revista de Filología Hispánica XXXIV

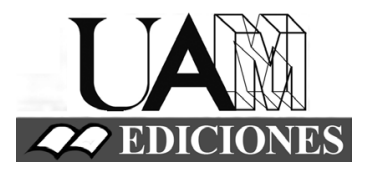




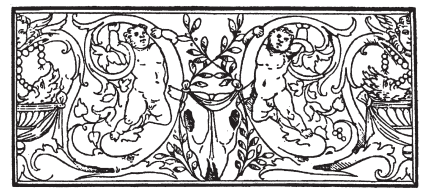

\section{Edad de Oro. Revista de Filología Hispánica}

ISSN: 0212-0429

Dirección:

Teodosio Fernández

Secretaría y edición:

José Ramón Trujillo

Comité científico internacional:

Carlos Alvar (Univ. de Ginebra)

Ignacio Arellano (Univ. de Navarra)

Javier Blasco (Univ. de Valladolid)

Alberto Blecua (UAB)

Jean Canavaggio (Univ. de París X)

Laura Dolfi (Univ. de Turín)

Aurora Egido (Univ. de Zaragoza)

Víctor García de la Concha (RAE)

Luciano García Lorenzo (CSIC)

Joaquín González Cuenca (Univ. de Castilla-

La Mancha)

Agustín de La Granja (Univ. de Granada)

Begoña López Bueno (Univ. de Sevilla)

Michel Moner (Univ. de Toulouse III)

Joan Oleza (Univ. de Valencia)

Alfonso Rey (Univ. de Santiago)

Lina Rodríguez Cacho (Univ. de Salamanca)

Leonardo Romero Tobar (Univ. de Zaragoza)

Aldo Ruffinatto (Univ. de Turín)

Lía Schwartz (City University of New York)
Redacción y admisión de originales:

Teodosio Fernández

Edad de Oro

Departamento de Filología Española

Universidad Autónoma de Madrid

28049 Madrid (España)

Tfno.: +0034914974090

correo: teodosio.fernandez@uam.es

Distribución, suscripción y venta:

Servicio de Publicaciones de la UAM

Universidad Autónoma de Madrid

28049 Madrid (España)

Intercambio de publicaciones:

Biblioteca de la Facultad de Filosofía y

Letras (UAM)

Universidad Autónoma de Madrid

28049 Madrid (España)

Han colaborado en este volumen:

Departamento de Filología Española (UAM)

Facultad de Filosofia y Letras (UAM)

Edad de Oro se recoge, entre otras, en las siguientes bases de datos: SCOPUS, MLA Database, HLAS, Latindex, PIO-Periodical Content Index, ISOC, Dialnet, MIAR, ERIH, DICE, Sumaris CBUC, Ulrich's. Se encuentra evaluada en CIRC: A; INRECH; MIAR difusión ICDS live: 9.977; SCImago Journal \& Country Rank: H Index 2, SJR 0,101, Q4; RESH índice de impacto: 0.041; ERIH: A INT1; Carhus Plus+ 2014: C. 